\title{
NASIONALISME MASYARAKAT GUNUNG KAWI DALAM MELESTARIKAN ADAT DAN BUDAYA KESENIAN PAGELARAN PEWAYANGAN
}

\author{
Endrise Septina R. \\ endriseseptina@gmail.com \\ Universitas Wisnuwardhana Malang
}

\begin{abstract}
Nationalism is a sense of patriotism that is mandatory for all Indonesians. However, with the influx of globalization, it has made the fading of nationalism even worse for future generations. The fading sense of nationalism threatens the continuation of Indonesia's cultural heritage. Various kinds of culture in Indonesia, for example puppet shows, reog, remo dance, ngaben, and so on. Gunung Kawi is a volcano located in Malang Regency, East Java Indonesia. There are religious and cultural tourism in Gunung Kawi, including the Eyang Djugo and Eyang Raden Mas Imam Sudjono cemeteries, ciamsi, wayang performances, and reog. This paper is intended to add insight to the wider community that with the puppet show in Gunung Kawi is one of the preservation of Indonesian culture and a manifestation of the nationalism of the Gunung Kawi community. This study uses a qualitative approach. Data sources consist of library sources and respondents selected using purposive sampling method. Data collection techniques use documentation and interview studies. Data analysis uses inductive analysis. The results showed that the wayang performances held at Gunung Kawi were derived from cultural heritages which were hereditary and preserved by residents around Gunung Kawi, supported by both local and national tourists.
\end{abstract}

Key word: Nationalism, the culture of puppet arts, puppet shows

\begin{abstract}
ABSTRAK
Nasionalisme adalah rasa cinta tanah air yang wajib dimiliki bagi seluruh rakyat Indonesia. Namun, dengan masuknnya arus globalisasi membuat semakin memudarnya nsionalisme bagi generasi penerus. Memudarnya rasa nasionalisme mengancam kelanjutan warisan budaya yang di miliki Indonesia. Berbagai macam kebudayaan yang ada di Indonesia contohnya pagelaran pewayangan, reog, tari remo, ngaben, dan lain sebagainya. Gunung Kawi adalah sebuah gunung berapi yang terletak di Kabupaten Malang, Jawa Timur Indonesia. Di Gunung Kawi terdapat wisata religi dan kebudayaan diantara lain pemakaman Eyang Djugo dan Eyang Raden Mas Imam Sudjono, ciamsi, pagelaran pewayangan, dan reog. Tulisan ini dibuat bertujuan untuk menambah wawasan kepada masyarakat luas bahwa dengan adanya pagelaran pewayangan di gunung kawi merupakan salah satu mlestarikan kebudayaan bangsa Indonesia dan wujud dari nasionalisme masyarakat Gunung Kawi. Penelitian ini menggunakan pendekatan kualitatif. Sumber data terdiri dari sumber kepustakaan dan responden yang dipilih dengan menggunakan metode purposive sampling. Teknik pengumpulan data menggunakan studi dokumentasi dan wawancara. Analisis data menggunakan analisis induktif. Hasil penelitian menunjukkan bahwa pagelaran pewayangan yang diadakan di Gunung Kawi berasal dari
\end{abstract}


warisan budaya yang turun temurun dan dilestarikan oleh penduduk di sekitar gunung kawi, didukung oleh wisatawan baik local maupun nasional.

\section{Kata Kunci: nasionalisme, budaya kesenian pewayangan, pagelaran pewayangan}

\section{PENDAHULUAN}

Kemajuan dibidang teknologi dan informasi semakin memudahkan akses informasi dari negara satu dengan negara lainnya. semakin mudah akses informasi yang diperoleh maka akan mudah juga budaya-budaya suatu bangsa dipelajari. The Internet may be a meaningful medium for supporting a strong civil society and building social capital because of its relational social network features (Kim, 2011: 809). Dapat diartikan bahwa internet dapat menjadi sarana yang baik untuk mendukung masyarakat menjadi masyarakat yang kuat dan membangun jaringan sosial berdasarkan relasinya di dunia global. Apabila internet bisa dimnafaatkan dengan baik maka akan tercipta hal positif namun kadang penyalah gunaan internet semakin melemahkan rasa nasionalisme terhdap kebudayaan yang ada di Indonesia. Padahal, semakin melemah pelestarian budaya yang dimiliki oleh Indonesia akibatnya banyak pengakuan dari negara lain untuk mengklaim budaya negara kita.

Melemahnya batas antara negara satu dengan negara lainnya akan menyebabkan lunturnya rasa cinta tanah air ataun nasionalisme. Kecenderungan dan gaya hidup yang berkembang di negara maju akan ditiru oleh negara yang sedang berkembang, dalam hal ini negara Indonesia. Pola hidup konsumerisme dan hedonistic yang tumbuh subur di masyarakat Barat dengan budaya individualisme, perlahan mencemari budaya luhur bangsbangsa Timur yang terkenal santun dan memiliki semangat kolektivisme kuat (Murdiono, 2014 174). Kecenderungan meniru gaya hidup dan budaya negara lain tanpa menggunakan filterisasi nilai-nilai Pancasila maka akan melunturkan ciri khas kita sebagai bangsa Indonesia.

\begin{tabular}{llr}
\multicolumn{2}{c}{ Budaya merupakan bahasa } \\
sansekerta yaitu buddhaya yang
\end{tabular} mempunyai arti bahwa segala sesuatu yang ada hubungannya dengan akal dan budi manusia. Secara hariah budaya dapat diartikan cara hidup yang dimilki sekelompok masyarakat yang diwariskan terun temurun kepada generasi berikutnya. Indonesia merupakan negara yang kaya akan adat dan budaya, dari sabang sampai merauke terbentang luas wilayah negara Indonesia yang kaya akan adat dan budayanya. Pentingnya kebudayaan untuk mengembangkan suatu pendidikan dalam budaya nasional mengupayakan, melestarikan dan mengembangkan nilai budaya-budaya dan pranata sosial dalam menunjang proses pengembangan dan pembangunan nasional serta melestarikan nilai-nilai luhur budaya bangsa. Kebudayaan merupakan warisan sosial, seperti bahasa, dapat dipindahkan dari generasi ke generasi selanjutnya(Mohammad Bahar, 2017 72). Untuk menjaga kelestarian budaya harus turun-temurun dan berkelanjutan dari generasi-kegenerasin agar budaya tersebut tidak punah termakan oleh zaman.

Berbagai macam kebudayaan yang ada di Indonesia salah satunya adalah budaya wayang. Wayang adalah seni pertunjukan yang telah ditetapkan sebagai warisan budaya asli Indonesia. Wayang merupakan seni pertunjukkan bayangan yang dibawakan oleh dalang sebagai sutradara dalam pertunjukan pewayangan. Wayang kulit merupakan jenis wayang yang 
berasal dari Jawa Timur. Biasanya pagelaran pewayangan hanya digelar pada acara-acara besar misalnya ruwah desa atau dikenal dengan istilah membangun desa atau memelihara desa. Namun, di Gunung Kawi pagelaran pewayangan hampir setiap hari digelar baik pada siang hari maupun malam hari.

\section{METODE}

Penelitian ini menggunakan pendekatan kualitatif karena menekankan pada realitas sosial di masyarakat. Pada penelitian kualitatif, peneliti menggunakan dan mengumpulkan berbagai macam data empiris yang menggambarkan peristiwaperistiwa yang dialami. Pendekatan penelitian kualitatif adalah penelitian yang berlandaskan filsafat postsitivisme, digunakan untuk meneliti pada kondisi obyek yang alamiah, dimana peneliti adalah sebagai instrumen kunci (Sugiyono, 2013:15). Peneliti berperan penuh dalam penelitian dimana peneliti sebagai instrument kunci yang harus menggali data secara menyeluruh, lalu menelaahnya, kemudian menafsirkannya, untuk itu seorang peneliti harus cerdas dalam memilah dan mengolah data yang telah diperoleh di lapangan.

Sumber data pertama merupakan sumber bahan kepustakaan yang meliputi buku teks, dokumen-dokumen, jurnal, makalah, dan surat kabar yang berkaitan dengan nasionalisme dalam melestarikan kebudayaan pagelaran pewayangan. Sumber data kedua berasan dari responden yang dipilih menggunakan metode purposive sampling, yang terdiri dari wawancara kepada dhalang, bu lurah wonosari, pak lurah wonosari, petugas keamanan Gunung Kawi, petugas pusat informasi Gunung Kawi, masyarakat sekitar gunung kawi (penjual bunga, penjual makanan, dan penjual cindera mata).
Teknik pengumpulan data menggunakan studi dokumentasi dan wawancara. Analisis data menggunakan analisis induktif, yaitu proses pembahasannya berasal dari data yang telah ditentukan. Teknik analisis data yang dikemukakan oleh Sugiyono (2013) yang meliputi tiga kegiatan yaitu: 1) Reduksi Data, 2) Penyajian Data, 3) Verifikasi Data. Mereduksi data artinya dalam penelitian ini peneliti harus merangkum dan memilih data yang pokok dan memfokuskan pada hal-hal yang penting dengan demikian peneliti akan mempermudah melakukan pengumpulan data selanjutnya. Setelah mereduksi data maka peneliti melakukan penyajian data yang telah diperoleh dari lapangan dalam hal ini Gunung Kawi. Langkah terakhir yaitu verifikasi data atau penarikan kesimpulan, peneliti dapat menarik kesimpulan berdasarkan data yang telah ditemukan dan direduksi.

\section{HASIL DAN PEMBAHASAN}

\section{Pagelaran Pewayangan Di Gunung Kawi}

Gunung Kawi adalah sebuah gunung berapi yang terletak di Kabupaten Malang, Jawa Timur Indonesia. Gunung Kawi terletak di Wonasari yang merupakan sebuah desa yang terletak di dataran tinggi Kabupaten Malang, Provinsi Jawa Timur. Desa wonosari terletak di dataran tinggi malang dan terdapat salah satu wisata religi yang dikenal dengan sebutan nama "Pesarean Gunung Kawi". Pesarean Gunung Kawi merupakan salah satu objek wisata yang banyak mengandung unsur kebudayaan dan unsur religi karena di Gunung Kawi terletak makam "Eyang Djugo" yang merupakan tokoh masyarakat yang membawa ajaran agama islam bagi masyarakat sekitar.

Gunung Kawi merupakan pesarean atau makam dari Mbah Djugo dan Raden Mas Imam Sudjono, ketika ada pengunjung 
yang datang untuk berdoa maka ada tata cara sendiri yang dilakukan dengan membawa bunga tabur untuk ditebarkan dipusara menggunakan perantara seorang cantrik yang dengan ijin juru kunci makam untuk meletakkan bunga tabur di pusara makam Mbah Jugo dan Raden Mas Imam Sudjono. Setelah ritual berdoa kita akan mendapatkan bunga layon dari cantrik sebagai souvenir yang berbentuk segitiga sebagai oleh-oleh dari Gunung Kawi yang bisa digunakan untuk campuran obad. Bunga-bunga untuk di pesarean dapat dibeli seharga Rp 5.000-25.000. Pesarean Gunung Kawi di buka dari jam 16.00 sore sampai jam 4.00 dini hari atau 12 jam pada hari Jum'at Legi.

Pengunjung yang datang ke Pesarean Gunung Kawi berasal dari berbagai macam daerah bahkan mayoritas berasal dari etnis cina, oleh karena itu di Gunung Kawi ada 2 tempat peribadatan yaitu masjid dan vihara yang berdekatan. Selain itu ada salah satu tempat yang ramai oleh pengunjung yaitu ciamsi yang merupakan tempat ramala. Ciamsi merupakan ramalan kebudayaan tionghoa yang bertujuan dapat membantu persoalan hidup yang sedang dihadapi, di kuil ciamsi biasanya ada 2 penjaga yang dapat membantu kita menafsirkan arti dari ramalan yang kita dapat. Pesarean yang ada di Gunung Kawi dikelola oleh yayasan ngesti gondo. Yayasan ngesti gondo berdomisili di Desa Wonosari Kec. Wonosari Kab Malang, menaungi lokasi makam Eyang Djugo dan Raden Mas Imam Soedjono yang sering disebut Twa Law She dan Dji Law She.

Pagelaran Pewayangan yang ada di Gunung Kawi berasal dari kebiasaan Eyang Jugo yang merupakan tokoh masyarakat Gunung Kawi yang menyebarkan agama islam melalui media wayang kulit dan gending-gending Jawa. Sepeninggal Eyang Djugo dan Raden Mas Imam Sudjono pagelaran wayang kulit tetap dilestarikan. Setelah tahun 1957 pagelaran pewayangan di pesarean Gunung Kawi berkembang semakin pesat. Hampir setiap hari selalu ada pagelaran wayang kulit di wilayah Gunung Kawi, baik itu siang hari maupun malam hari berdasarkan jadwal yang telah ditentukan, ada penonton atau tidak tetap berlangsung pagelaran wayang kulit di Gunung Kawi. Pagelaran pewayangan yang ada di Gunung Kawi biasanya berasal dari perintaan para pengunjung yang telah sukses atau mendapatkan apa yang telah diinginkan dan wujud dari rasa syukur mereka.

Berdasarkan hasil wawancara dari Dhalang Gatot cerita pewayangan berasal dari permintaan dari sang penanggap wayang, misalkan saja penanggap wayang mengisahkan ingin punya anak lalu terlaksana maka orang tersebut memesan cerita yang sama dengan kehidupan pribadianya. Ada juga yang mengisahkan tentang kesuksesan seseorang yang berawal dari kesengsaraan, ada juga yang meminta tanggapan pagelaran pewayangan hanya untuk meruwah tempat usaha atau kantornya. Ruwah adalah istilah lain dari merawat, artinya merawat lingkungan kerja agar selalu stabil dan kondusif. Pagelaran pewayangan dalam satu hari bisa dilakukan 2x dari mulai jam 14.00 siang sampai jam 22.00 malam atau dari jam 22.00 sampai jam 04.00 dini hari. Pagelaran pewayangan terus berlangsung meskipun tidak ada penonton, atau hujan dan mati lampu sekalipun. Hal ini demi totalitas dan konsistensi dari dhalang berdasarkan amanat yang telah diberikan oleh penanggap wayang. Pagelaran pewayangan biasanya diadakan karna rasa syukur, nadzar, atau ruwatan oleh penanggap. 
Nasionalisme Masyarakat Gunung Kawi Dalam Melestarikan Adat Dan Budaya Kesenian Pagelaran Pewayangan

\section{Kebudayaan Indonesia yang-menjadi} adalah suatu Weltanschauung, artinya pegangan setiap insan dan setiap identitas budaya mikro Indonesia, sebagai suatu value system yang baru, memerlukan suatu proses perwujudannya antara lain melalui proses dalam pendidikan nasional maka oleh sebab itu, di tengah-tengah maraknya identitas kesukuan, sekaligus perlu ditekankan sistem nilai baru yang akan kita wujudkan, yaitu sistem nilai keindonesiaan, R. Ibnu Ambarudin (2016). Untuk melestarrikan kebudayaan pada suatu daerah haruslah dirancang sistem nilai ke Indonesiaan, bukan lagi kesukuan karena warisan budaya pada suatu suku adalah warisan budaya sebuah bangsa.

Bachtiar Alam (1998) Sumbangsih

yang dapat diberikan oleh Antropologi dalam menghadapi era globalisasi seperti ini adalah dengan mengungkapkan kodrat setiap kebudayaan yang bersifat dinamis, cair dan hibrid dengan menghindari serta mengkritik representasi budaya yang bersifat esensialis dan statis. Dengan kesadaran karakteristik dinamika kebudayaan yang demikian, kita menjadi sadar bahwa proses globalisasi dan perubahan budaya selalu dari kehidupan sosial manusia. Proses globalisasi memang tidak dapat dihindari karena selalu mengikuti dinamika kehidupan manusia, hanya saja bagi masyarakat Indonesia agar tidak tergerus arus globalilasi maka dapat menggunakan Pancasila sebagai filter dalam kehidupan sehari hari.

Pancasila merupakan dasar dari segala sumber hukum baik itu norma hukum nasional dan norma hukum agama. Pancasila adalah pedoman kuat bagi masyrakat Indonesia dalam menghadapi berbagai macam tantangan dalam kehidupan berbangsa dan bernegara. Era globalisasi yang mengaburkan batas-batas antara negara satu dan negara lain dapat menghilangkan kebudayaan masyarakat Indonesia secara perlahan karena dengan mudahnya budaya asing yang masuk ke Indonesia. Beberapa dari anak muda bahkan malu dengan kebudayaan yang dimiliki bangsanya dan lebih bangga dengan budaya asing yang telah masuk ke Indonesia, hal tersebut bila terjadi terus menerus maka kebudayaan yang ada di Indonesia akan hancur dan punah. Untuk itu dibutuhkan rasa nasionalisme yang tinggi agar dapat mempertahankan warisan budaya Indonesia.

Penanaman nasionalisme harus dimulai sejak dini agar mendarah daging pada generasi selanjutnya. So if nasionalism was not an expression of nations, classes or intelligentsias, if its roots were not to be found in the study of nation, capitalism, classes or ideas, how was it to be understood? Geller (2006). Jadi jika nasionalisme bukanlah ekspresi bangsa, kelas atau inteligensia, jika akarnya tidak ditemukan dalam studi tentang bangsa, kapitalisme, kelas atau ide, bagaimana bisa dipahami oleh suatu bangsa. Jadi nasionalisme dapat diekspresikan melalui kebudayaan dari suatu bangsa maupun ideide yang dihasilkan oleh individu masingmasing masyarakat. Catherine Frost (2006: 91) menjelaskan;

The drive to define the national character and to establish its inherent indigeneity also paid dividends in terms of national mobilization. Having one true ideal of the national character makes it easier to concentrate collective resources on a single performative effort. Once this conceptual element is added to the mix that only this national character will do, and that only through it can a people flourish-then the pieces are in place for a complete inversion of the nationalist logic. An essentialist variant then easily flows from the desire to define a national character, and more specifically, to rally 
people around a particular understanding of the nation."

Dapat ditarik kesimpulan bahwa dorongan untuk mendefinisikan karakter nasional adalah membangun sifat aslinya dalam mobilisasi nasional. Memiliki satu karakter dari suatu karakter nasional akan lebih mudah membuat individu memiliki sumber daya manusia yang berkarakter sesuai identitas nasionalnya. Karakter nasional didefinisikan sebagai persamaan yang menunjukkan ciri khas suatu bangsa.

Identitas sebuah bangsa berasal dari budayanya, pewayangan adalah salah satu budaya yang ada di Indonesia. Masyarakat Gunung Kawi sudah sejak 1957 telah melestarikan pagelaran pewayangan yang artinya nasionalisme telah tertanam sejak awal kemerdekaan Indonesia.
Nasionalisme di Indonesia dewasa ini telah memudar sedikit demi sedikit karena tergerus dengan perubahan zaman dan berkembangnya era globalisasi. Untuk itu penanaman nasionalisme melalui pelestarian kebudayaan sudah sangat tepat.

Nasionalisme masyarakat di Gunung Kawi dapat dilihat dari cara masyarakat melestarikan budaya dan adat istiadat yang sudah ada sejak jaman dahulu. Budaya pagelaran pewayangan yang sudah ada sebelum 1957 hingga saat ini masih terjaga dengan baik, selain pewayangan masyarakat sekitar Gunung Kawi pun masih menjaga tradisi melakukan penyekeran ke pesarean atau makam Eyang Djugo dan Raden Mas Imam Soedjono yang sering disebut Twa Law She dan Dji Law She pada malam Jum'at Legi.

\section{Gambar. 1. Pagelaran Pewayangan di Gunung Kawi}

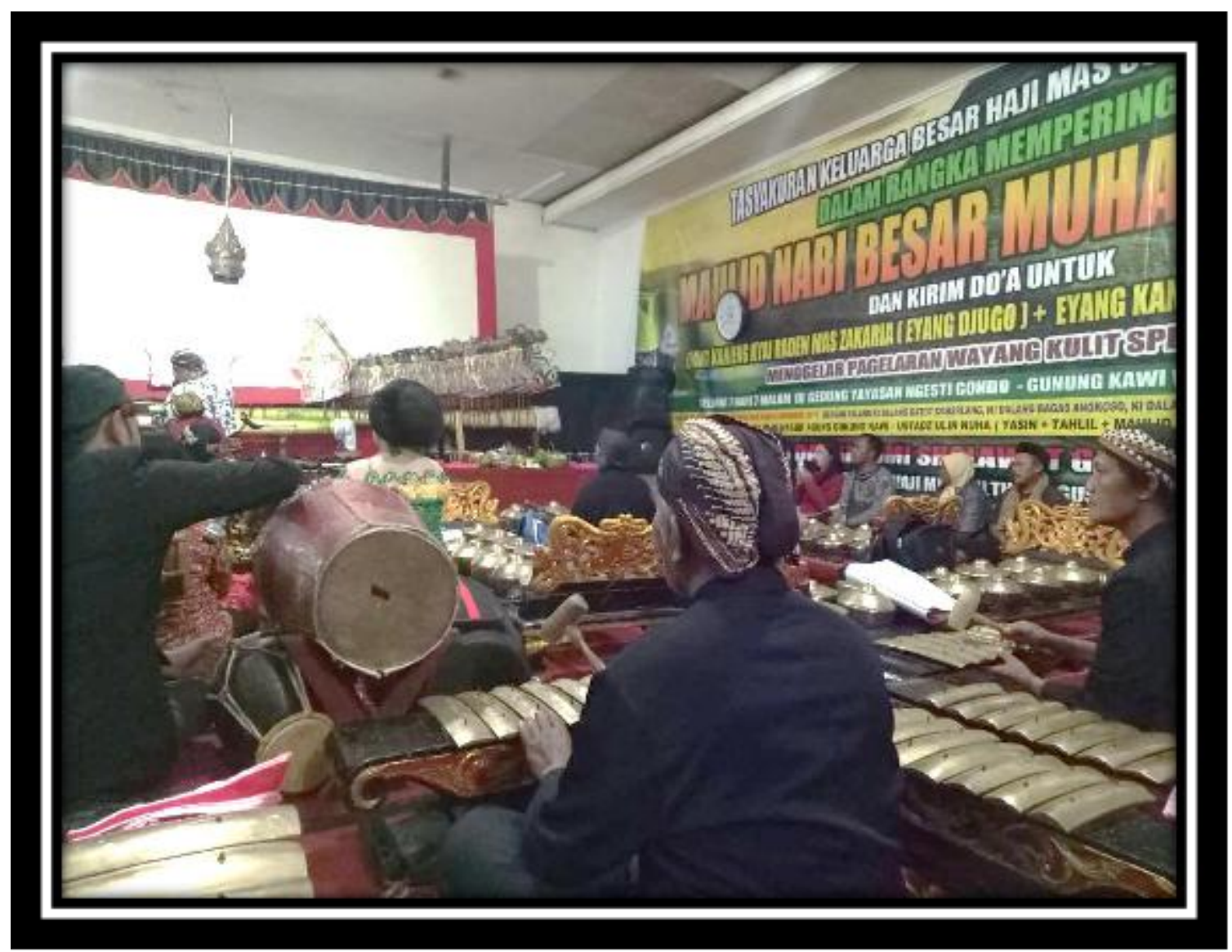


Tradisi yang ada di Gunung Kawi pada malam Jum'at Legi ada bermacammacam yaitu ziarah kubur, reog, sholawatan yang diadakan di masjid sekitar wilayah makam dan pagelaran pewayangan. Pagelaran pewayangan tidak hanya dilakukan pada malam Jum'at Legi saja, namun setiap hari tergantung dari permintaan dari penanggap wayang. Cerita pewayangan berasal dari permintaan penanggap wayang, misalkan saja penanggap wayang mengisahkan ingin punya anak lalu terlaksana maka orang tersebut memesan cerita yang sama dengan kehidupan pribadianya. Ada juga yang mengisahkan tentang kesuksesan seseorang yang berawal dari kesengsaraan, ada juga yang meminta tanggapan pagelaran pewayangan hanya untuk meruwah tempat usaha atau kantornya. Ruwah adalah istilah lain dari merawat, artinya merawat lingkungan kerja agar selalu stabil dan kondusif. Pagelaran pewayangan dalam satu hari bisa dilakukan $2 \mathrm{x}$ dari mulai jam 14.00 siang sampai jam 22.00 malam atau dari jam 22.00 sampai jam 04.00 dini hari. Pagelaran pewayangan terus berlangsung meskipun tidak ada penonton, hal ini demi totalitas dan konsistensi dari dhalang berdasarkan amanat yang telah diberikan oleh penanggap wayang. Pagelaran pewayangan biasanya diadakan karna rasa syukur, nadzar, atau ruwatan oleh penanggap wayang.

\section{KESIMPULAN}

Potensi yang dimiliki oleh gunung Kawi sebagai wisata religi dan kebudayaan mampu membuat turis nasional datang untuk berkunjung, terlebih lagi pada malam Jumat Legi. Potensi yang dimiliki gunung Kawi haruslah terjaga dengan baik dan terus dikembangkan, karena dengan ini salah satu warisan bangsa tetap terjaga dengan baik. Pagelaran pewayangan yang selalu diadakan di Gunung Kawi merupakan wujud dari nasionalisme bagi masyrakat sekitar yang tetap melestarikan kebudayaan pewayangan bahkan pengunjung maupun penanggap wayang pun ikut melestarikan kebudayaan pegalaran pewayangan.

\section{DAFTAR PUSTAKA}

Alam, Bachtiar. (1998). Globalisasi dan Perubahan Budaya: Perspektif Teori Kebudayaan1 Bachtiar Alam (Universitas Indonesia). Jurnal Antropologi Indonesia 54,

Ambarudin, R. Ibnu. (2016) Pendidikan Multikultural untuk Membangun Banmgsa yang Nasionalis Religiusn. Jurnal Civics Vol. 13 No. 1, Juni 2016

Bahar, Muhammad Akkase. (2017). Filsafat Kebudayaan Dan Sastra (Dalam Perspektif Sejarah). Jurnal ilmu budaya volume 5, nomor 1, juni 2017, issn 2354-7294

Ernes, Geller. (2006). Nation and Nationalism Seccond Edition. Cornell University Press. Itacha: New York.

Frost, Catherine. (2006). Morality and Nationalism. published in the Taylor \& Francis e-Library, 2006

Joon Kim1 , Andrea L. Kavanaugh2, and Karen M. Hult2. (2011). Civic Engagement and Internet Use in Local Governance: Hierarchical Linear Models for Understanding the Role of Local Community Groups B.. dalam Administration \& Society, 43 (7), hlm. 807-835

Murdiono, Mukhammad dkk. (2014). Membangun Wawasan Global Warga Negara Muda Berkarakter Pancasila. Jurnal Pendidikan Karakter, Tahun IV, Nomor 2, Juni 2014

Sugiono. (2014). Metode penelitian pendidikan (pendekatan kuantitatif, kualitatif, dan R\&D).

Bandung: Alfabeta. 